\title{
Pengaruh Kadar Hb dan Paritas dengan Kejadian Intra Uterine Fetal Death (IUFD) di RSUD Arifin Achmad Pekanbaru. \\ Associated $\mathrm{Hb}$ and Parity with the Incidence of Intra Uterine Fetal Death (IUFD) General Hospital Arifin Achmad Pekanbaru
}

\section{Ani Triana}

Program Studi Magister Ilmu Kesehatan Masyarakat STIKes Hang Tuah Pekanbaru

\begin{abstract}
ABSTRAK
Intra Uterine Fetal Death (IUFD) adalah janin mati dalam rahim dengan berat badan $\geq 500$ gram atau kematian janin dalam rahim pada kehamilan 20 minggu atau lebih. Data yang diperoleh dari Rekam Medik RSUD Arifin Achmad Pekanbaru dari tahun 2009 sampai 2011 untuk kejadian IUFD mengalami peningkatan. Pada tahun 2009 proporsi kejadian IUFD 3,6\% dari 2929 persalinan. Pada tahun 2010 proporsi kejadian IUFD meningkat 4,2 \% dari 2989 persalinan. Pada tahun 2011 proporsi meningkat 4,4 \% dari 2856 persalinan. Tujuan penelitian adalah diketahuinya faktor resiko Kejadian IUFD di RSUD Arifin Achmad Pekanbaru tahun 2010-2011. Desain penelitian yang digunakan adalah studi kasus kontrol (case control study). Kasus yaitu janin mati di dalam rahim yang dilahirkan oleh ibu di RSUD Arifin Achmad Pekanbaru tahun 2010-2011 periode Januari 2010-Desember 2011 dan kontrol yaitu bayi yang dilahirkan hidup oleh ibu di RSUD Arifin Achmad Pekanbaru tahun 2010-2011 periode Januari 2010-Desember 2011. Hasil penelitian ibu yang memiliki kadar $\mathrm{Hb}<11$ gr \% lebih berisiko melahirkan IUFD 3 kali (CI 95\% 1,9-4,9) dibandingkan ibu yang memilki kadar $\mathrm{Hb} \geq 11 \mathrm{gr} \%$, ibu yang memiliki paritas 0 dan $>4$ lebih berisiko melahirkan dengan IUFD 1,5 kali (CI 95\% 1-2,1) dibandingkan ibu yang memiliki paritas 1-4. Kesimpulan yaitu variabel independen yang memiliki hubungan sebab akibat dengan kejadian IUFD adalah kadar Hb dan paritas. Saran ditujukan bagi tenaga kesehatan yaitu aktif dalam memberikan penyuluhan, bagi RSUD Arifin Achmad Pekanbaru perlu keaktifan dalam melaksanakan AMP, dan bagi ibu hamil dan keluarga yaitu ikut serta dalam pemeriksaan kehamilan dan program KB.
\end{abstract}

Kata Kunci: Kadar Hb, Paritas, Kejadian IUFD, RSUD Arifin Achmad

\section{ABSTRACT}

IntraUterineFetalDeath(IUFD) is adead fetusin the wombweighing $\geq 500$ gramsordeath ofthe fetus in thewombat 20 weeksormore. Data obtainedfrom theMedical RecordsGeneral HospitalArifinAchmadPekanbarufrom 2009 to2011 toincreasethe incidence ofIUFD. In 2009the proportion ofthe incidence ofIUFD3.6\%of2929deliveries.In 2010the proportion ofIUFDincidenceincreased $4.2 \%$ from 2989deliveries. In 2011the proportionincreased $4.4 \%$ from 2856deliveries. The purposeof researchisknownrisk factorin theincidence ofIUFDGeneral Hospital Arifin Achmad Pekanbaru2010-2011.The designstudy is acase-control study(casecontrol study). The case ofthedead fetusin the wombwere born tomothersin General Hospital Arifin Achmad Pekanbaruin 2010-2011periodJanuary 2010-December 2011 andthe controlinfants born tomotherslivingin General Hospital Arifin Achmad Pekanbaru2010-2011periodJanuary 2010-December 2011. The resultsof women havingHb $<11 \mathrm{~g} \%$ higher risk of havingIUFD3 times(95\% CII.9 to 4.9) than those whohave theHb level $\geq 11 \mathrm{~g} \%$, mothers withparity0 and $>4$ moreriskybearwithIUFD1.5 times(95\% CI1 to 2.1) compared towomen whohadparity 1-4. The conclusionthatthe independentvariablesthat havea causal relationshipwith the incidence ofIUFDishemoglobinandparity. Adviceisintended forhealth professionalsactive inproviding information, forGeneral Hospital Arifin Achmad Pekanbaruneed tobe active inimplementingAMP, andfor pregnant womenand families that participate inprenatal careandfamily planning.

Keyword: Hemoglobin concentration, Parity, the incidence ofIUFD, General Hospital Arifin Achmad Pekanbaru

\section{PENDAHULUAN}

Menurut World Health Organization (WHO)dan The American College of Obstetricians and gynecologist yang disebut Intra Uterine Fetal Death (IUFD) adalah janin yang mati dalam rahim dengan berat badan 500 gram atau lebih atau kematian janin dalam rahim pada kehamilan 20 minggu atau lebih (Saefudin, 2010). IUFD termasuk dalam masalah perinatal yang merupakan salah satu indikator kesehatan, sehingga hal ini sangat sensitif karena berhubungan dengan kesehatan ibu dan perinatal. IUFD merupakan salah satu penyebab kematian perinatal (Winkjosastro, 2005).

Dari data pusat statistik kesehatan nasional tahun 2003 menunjukkan di Amerika Serikat frekuensi IUFD sebesar 6,9 per 1000 kelahiran. Sedangkan di negara berkembang masih belum didapatkan data yang

Alamat Korespodensi: Ani Triana, STIKes Hang Tuah Pekanbaru Jl. Mustafasari No 05, HP: 081210960607, email: triana_aniz@yahoo. 
valid akibat sistem pelaporan yang kurang baik (Lindsey, 2008). Sedangkan kasus IUFD di Indonesia sendiri tidak diketahui dengan pasti karena belum ada survey yang menyeluruh (Prawirohardjo, 2007).

IUFD terjadi tanpa sebab yang jelas, yang mengakibatkan kehamilan tidak sempurna (uncomplicated pregnancy). Namun ada beberapa faktor yang berhubungan dengan kejadian IUFD yaitu faktor ibu, faktor janin dan faktor kelainan tali pusat (termasuk plasenta) (Winkjosastro, 2005).

Data yang diperoleh dari Rekam Medik RSUD Arifin Achmad Pekanbaru dari tahun 2009 sampai 2011 untuk kejadian IUFD mengalami peningkatan. Pada tahun 2009 proporsi kejadian IUFD sebanyak 106 kasus $(3,6 \%)$ dari 2929 persalinan. Pada tahun 2010 proporsi kejadian IUFD meningkat sebanyak 125 kasus $(4,2 \%)$ dari 2989 persalinan. Pada tahun 2011 proporsi meningkat yaitu sebanyak 125 kasus $(4,4 \%)$ dari 2856 persalinan. Dari tahun 2009-2011 kejadian IUFD masih termasuk dalam 10 kasus obstetrik dan tindakan di Instalasi Rawat Inap Camar I dan II (Rekam Medik, 2011).

Hal ini merupakan masalah kesehatan yang serius karena IUFD dapat meningkatkan angka kematian perinatal. Seharusnya IUFD dapat dicegah apabila dilaksanakan pencegahan terhadap faktorfaktor penyebab IUFD. Selain itu dari data perpustakaan di RSUD Arifin Achmad Pekanbaru belum ada yang melakukan penelitian tentang IUFD terutama faktor resiko kejadian IUFD. Tujuan Penelitian adalah diketahuinya faktor resiko Kejadian IUFD di RSUD Arifin Achmad Pekanbaru tahun 20102011.

\section{METODE}

Desain penelitian yang digunakan adalah studi kasus kontrol (case control study). Kasus yaitu janin mati di dalam rahim yang dilahirkan oleh ibu di RSUD Arifin Achmad Pekanbaru tahun 2010-2011 dan kontrol yaitu bayi yang dilahirkan hidup oleh ibu di RSUD Arifin Achmad Pekanbaru tahun 2010-2011. Dengan metode perhitungan ukuran sampel untuk desain kasus kontrol dengan: $\alpha 5 \%, \beta 10 \%$, OR $=2$, didapatkan 250 kasus dan 250 kontrol.

Prosedur pengambilan sampel mulai dilakukan bulan Desember 2011, diurutkan ke belakang sampai Januari 2010. Kasus dan kontrol didapatkan dari catatan rekam medik RSUD Arifin Achmad Pekanbaru. Jenis data yang dikumpulkan adalah data sekunder yaitu kasus dan bukan kasus kejadian IUFD yang sama-sama diambil dari sumber data yaitu rekam medis di RSUD Arifin Achmad Pekanbaru tahun 2010-2011 dengan menggunakan daftar cheklist. Data sekunder tersebut terdiri dari 5 variabel yang diteliti yaitu variabel komplikasi kehamilan, kadar $\mathrm{Hb}$, lama kehamilan, paritas dan umur.
Pengolahan data dilakukan dalam tahap-tahap editing, coding, processing, cleaning dan tabulating. Analisis data dilakukan yaitu analisis univariat, analisis bivariat dengan uji chi square dan analisis multivariat dengan multiple logistic regression.

\section{HASIL}

\section{Analisis Univariat}

Pada analisa univariat didapatkan hasil masih tingginya ibu hamil yang memiliki komplikasi kehamilan yaitu sebanyak 326 orang $(65,2 \%)$, masih ada ibu yang memiliki kadar $\mathrm{Hb}<11$ gr \% yaitu sebanyak 136 orang $(27,2 \%)$, lama kehamilan $>40 \mathrm{mg}$ yaitu sebanyak 177 orang $(35,4 \%)$, hamil pada usia yang berisiko yaitu usia ibu $<20$ dan $>35$ tahun sebanyak 124 orang, serta masih tingginya ibu hamil dengan paritas yang berisiko yaitu paritas 0 dan $>4$ sebanyak 253 orang $(50,6 \%)$.

\section{Analisis Bivariat}

Dari hasil analisis bivariat didapatkan 4 variabel yang berhubungan secara signifikan yaitu komplikasi kehamilan ( $p$ value $=0,004)$, kadar $\mathrm{Hb}(p$ value $=0,007)$, lama kehamilan $(p$ value $=0,001)$ dan paritas $(p$ value $=0,049)$. Hanya 1 variabel yang tidak berhubungan yaitu usia ibu ( $p$ value $=0,407$ ). Dari 4 variabel tersebut yang berhubungan secara signifikan, ada 2 variabel yang berlawanan dengan sub hipotesis yaitu variabel komplikasi kehamilan dan lama kehamilan.

Adapun hasil dari variabel yang berhubungan secara signifikan berturut-turut yaitu pertama untuk variabel kadar $\mathrm{Hb}$ didapatkan hasil bahwa ibu yang memiliki Kadar $\mathrm{Hb}<11$ gr \% berisiko melahirkan dengan IUFD 2 kali dibandingkan ibu yang memiliki kadar $\mathrm{Hb} \geq 11$ gr \% (OR = 2 (CI 95\% 1,2-2,6)), kedua yaitu variabel paritas didapatkan hasil bahwa ibu yang memilki paritas 0 dan $>4$ berisiko melahirkan dengan IUFD 1,4 kali dibandingkan ibu yang memiliki paritas 1-4 $(\mathrm{OR}=1,4 \quad(\mathrm{CI} 95 \%$ 1-2,1)) sedangkan untuk variabel yang berlawanan dengan sub hipotesis secara berturut-turut yaitu pertama untuk variabel komplikasi kehamilan didapatkan hasil bahwa ibu yang tidak ada komplikasi kehamilan berisiko melahirkan dengan IUFD 1,7 dibandingkan ibu yang ada komplikasi (OR $=0,57$ (CI 95\% 0,39-0,82)), seharusnya berdasarkan sub hipotesis yaitu ibu yang ada komplikasi kehamilan lebih berisiko melahirkan dengan IUFD dibandingkan ibu yang tidak ada komplikasi. Kedua yaitu variabel lama kehamilan didapatkan hasil bahwa ibu yang lama kehamilan $\leq 40$ minggu berisiko melahirkan dengan IUFD 2,5 kali dibandingkan ibu yang lama kehamilan $>40$ minggu, seharusnya berdasarkan sub hipotesis yaitu ibu yang lama kehamilan $>40$ minggu lebih berisiko dibandingkan ibu yang lama kehamilan $\leq 40$ minggu. 


\section{Analisis Multivariat}

Pada analisis multivariat didapatkan hasil yaitu semua variabel menghasilkan $p$ value $\leq 0,05$ sehingga variabel yang berhubungan bermakna dengan kejadian IUFD yaitu komplikasi kehamilan, kadar $\mathrm{Hb}$ ibu, lama kehamilan dan paritas. Variabel independen yang berhubungan positif dengan kejadian IUFD adalah kadar $\mathrm{Hb}$ dan paritas. Dari variabel tersebut adapun variabel yang paling dominan berhubungan dengan kejadian IUFD adalah kadar $\mathrm{Hb}$ ibu (OR $=3$ (CI 95\% 1,9-4,9)).

Tabel 1

Hasil Analisis Bivariat

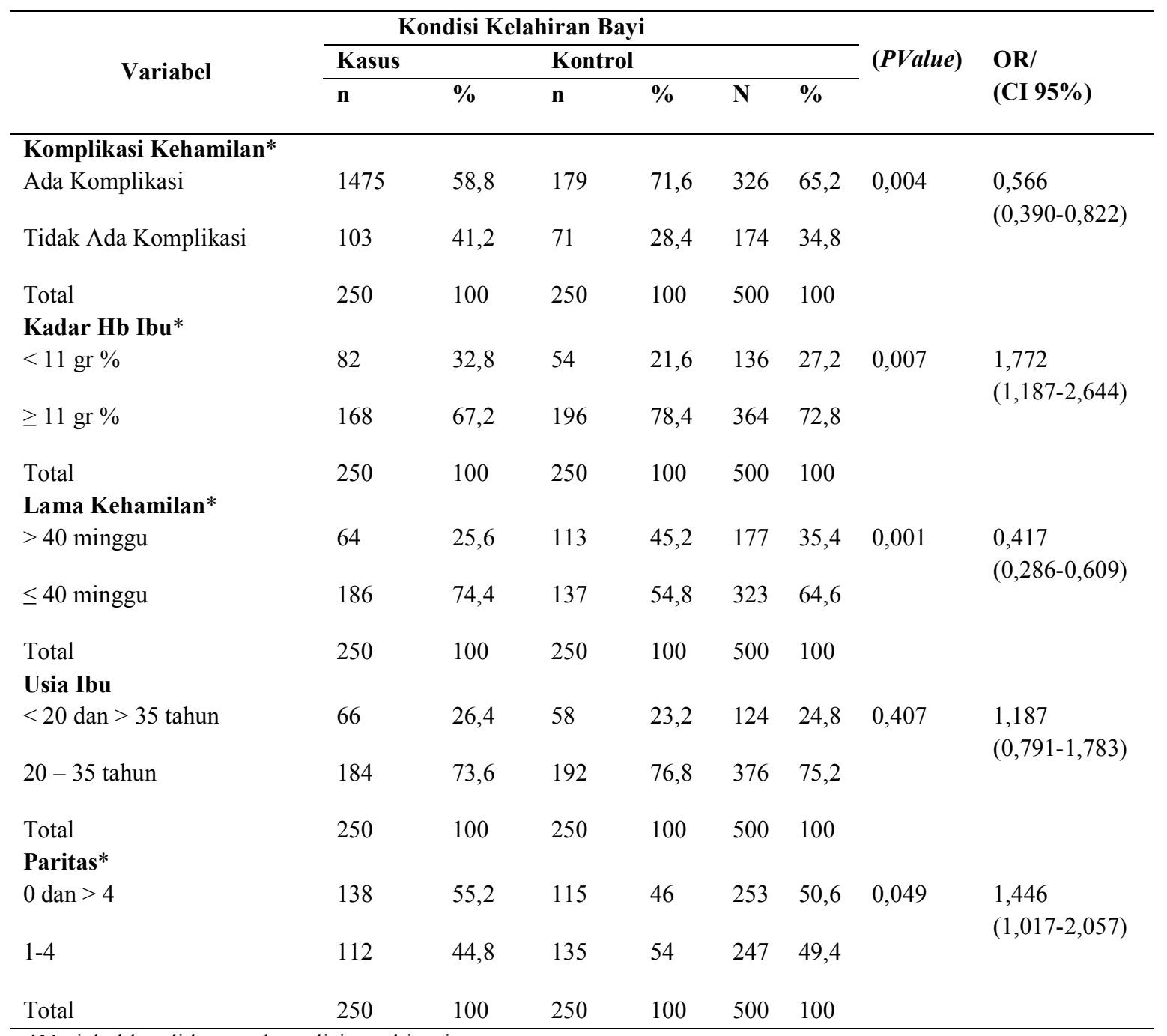

*Variabel kandidat untuk analisis multivariat

Signifikansi $(\alpha: 0,05)$

Tabel 2

Pemodelan Multivariat Akhir

\begin{tabular}{ccccc}
\hline Variabel & P value & OR & \multicolumn{2}{c}{ 95\% CI. For EXP (B) } \\
\cline { 4 - 5 } & & & Lower & Upper \\
\hline Komplikasi Kehamilan & 0,001 & 0,384 & 0,249 & 0,592 \\
Kadar Hb Ibu & 0,001 & 3,093 & 1,932 & 4,952 \\
Lama Kehamilan & 0,001 & 0,394 & 0,265 & 0,586 \\
Paritas & 0,037 & 1,485 & 1,024 & 2,154 \\
\hline
\end{tabular}




\section{PEMBAHASAN}

\section{Kualitas dan Akurasi Data}

Kualitas data ditentukan oleh relevansi data, validasi data, ketepatan waktu datangnya data dan kelengkapan, sedangkan akurasi data mencakup relevansi data, validitas dan reliabilitas data(Lapau, 2007). Relevansi data terjamin karena adanya kesesuaian antara data yang dikumpulkan dengan pencapaian tujuan khusus dan pembuktian hipotesis. Validitas eksternal pada penelitian ini tidak ada, validitas internal terdiri dari random error penelitian ini dengan sampel besar yang berjumlah 250 dan systematic error dimana terdapat bias seleksi yang tidak dapat dihindari pada variabel komplikasi kehamilan dan usia ibu dan kemungkinan bias informasi pada variabel lama kehamilan. Tidak ada bias pengacau (confounding bias) pada analisis multivariat. Reliabilitas data dalam penelitian ini tidak dapat ditentukan karena pengumpulan data hanya dilakukan satu kali.

\section{Kadar Hb}

Pada variabel kadar $\mathrm{Hb}$ ibu dimana untuk hubungan temporal $(+)$; karena ibu yang memiliki kadar $\mathrm{Hb}<11 \mathrm{gr} \%$ atau anemia diyakini mendahului terjadinya IUFD karena kurangnya asupan gizi dari ibu ke bayi. Untuk plausibility $(+)$ : ditemukannya teori yang mendukung, menurut Winkjosastro (2005) bahwa pada ibu hamil dengan anemia terjadi gangguan penyaluran oksigen dan zat makanan dari ibu ke plasenta dan janin, yang mempengaruhi fungsi plasenta. Fungsi plasenta yang menurun dapat mengakibatkan gangguan tumbuh kembang janin, abortus, partus lama, sepsis puerperalis, kematian ibu dan janin. Untuk konsistensi $(+)$ pada hasil penelitian ini sesuai dengan penelitian yang dilakukan oleh Nurchotimah (2008) dan untuk kekuatan asosiasi (+): kekuatan hubungan antara $\mathrm{Hb}<11 \mathrm{gr} \%$ ibu adalah sebesar 3kali (CI 95\% 1,9-4,9)artinya ibu yang memiliki kadar $\mathrm{Hb}<11$ gr \% berisiko melahirkan dengan IUFD 3 kali dibandingkan ibu yang memiliki kadar $\mathrm{Hb} \geq 11$ gr \%. Pada dose response relationship ()karena penelitian ini tidak menggunakan data kontinue sehingga sulit untuk dilakukan penilaian. Jenis disain studi (-): desain kasus kontrol mempunyai inferensi lemah karena data yang dimbil adalah data yang lalu.

Pada penelitian ini ditemukan bahwa kadar $\mathrm{Hb}$ ibu yang $<11$ gr \% menyebabkan terjadinya IUFD. Oleh karena itu untuk rekomendasi diperlukan upaya agar $\mathrm{Hb}$ ibu pada saat hamil lebih dari 11 gr \% yaitu dengan cara meningkatkan standar pelayanan ANC melalui program $14 \mathrm{~T}$ yang salah satunya adalah pemberian tablet Fe (Badan Litbangkes Depkes RI, 2001). Selain itu petugas kesehatan dapat memotivasi ibu hamil melalui konseling dan penyuluhan untuk mengkonsumsi makan-makanan yang banyak mengandung zat besi seperti sayur-sayuran hijau, hati, daging dan susu. Selain itu melakukan penyuluhan tentang bahaya anemia dengan menggunakan media seperti poster atau gambar-gambar, dengan begitu ibu lebih berhati-hati menjaga kehamilannya.

\section{Paritas}

Pada variabel paritas dimana untuk hubungan temporal (+), inidikarenakan paritas 0 dan $\geq 4$ diyakini mendahului terjadinya IUFD. Untuk plausibility $(+)$ karenaditemukannya teori yang mendukung yaitu menurut Wiknjosastro (2005) bahwa paritas yang berisiko melahirkan IUFD adalah paritas nol yaitu bila ibu pertama kali hamil dan paritas lebih dari empat. Makin tinggi paritas ibu maka makin kurang baik endometriumnya. Hal ini dapat berpengaruh pada kehamilan berikutnya karena kondisi rahim ibu belum pulih untuk hamil kembali diakibatkan oleh vaskularisasi yang berkurang ataupun perubahan atrofi pada desidua akibat persalinan yang lampau sehingga dapat mengakibatkan terjadinya kematian janin dalam kandungan. Untuk konsistensi (+) karena pada hasil penelitian ini memiliki korelasi dengan penelitian yang dilakukan oleh Kongkoli (2008). Untuk kekuatan asosiasi (+) karena kekuatan hubungan umur ibu adalah sebesar 1,5 kali (CI 95\% 1-2,2)artinya ibu yang memiliki paritas 0 dan $>4$ berisiko melahirkan dengan IUFD 1,5 kali dibandingkan ibu yang memiliki paritas 1-4. Untuk dose response relationship (-)karena penelitian ini tidak menggunakan data kontinue sehingga tidak dapat dinilai. Jenis desain studi (-) karena desain kasus kontrol mempunyai inferensi yang lemah.

Pada penelitian ini juga ditemukan bahwa ibu yang memiliki paritas 0 dan $>4$ menyebabkan terjadinya IUFD. Oleh karena itu untuk rekomendasi salah satu upaya untuk ibu yang paritasnya 0 atau disebut dengan nulipara (primigravida) agar dapat berhati-hati menjaga kehamilannya yaitu melalui pemeriksaan ANC secara lengkap dan teratur sehingga ada pemantauan untuk kondisi pertumbuhan dan perkembangan janin di dalam rahim untuk mencegah terjadinya IUFD. Rekomendasi untuk upaya yang dilakukan pada ibu yang memiliki paritas $>4$ agar menambah jumlah anak yaitu salah satu untuk mengurangi jumlah anak adalah melalui program Keluarga Berencana (KB) dengan mengajak Pasangan Usia Subur (PUS) yang memiliki banyak anak untuk berperan aktif menggunakan $\mathrm{KB}$ dan penyuluhan serta konseling untuk Metode Kontrasepsi Jangka Panjang (MKJP) salah satunya Metode Operatif Wanita (MOW) dan Metode Operatif Pria (MOP).

\section{Lama kehamilan}

Pada penelitian ini untuk variabel lama kehamilan berhubungan secara negatif, dimana dalam sub hipotesis bahwa ibu yang lama kehamilannya $>40$ minggu berisiko melahirkan IUFD sedangkan dalam 
penelitian ini ditemukan bahwa ibu yang lama kehamilannya $\leq 40$ minggu yang berisiko 2,5 kali melahirkan IUFD, kemungkinan ini karena adanya bias informasi yang tidak dapat dihindari. Untuk bias informasi bisa saja pasien lupa akan Hari Pertama Haid Terakhir (HPHT), menyebabkan petugas kesehatan memasukkan data lama kehamilan ibu hanya berdasarkan pemeriksaan yang ada sehingga terjadi kesalahan.

\section{Komplikasi kehamilan}

Pada penelitian ini untuk variabel komplikasi kehamilan berhubungan secara negatif, dimana dalam sub hipotesis bahwa ibu yang ada memiliki komplikasi kehamilan berisiko melahirkan IUFD sedangkan dalam penelitian ini ditemukan bahwa ibu yang tidak ada memiliki komplikasi kehamilan yang berisiko 2,5 kali melahirkan IUFD, kemungkinan ini karena adanya bias seleksi yang tidak dapat dihindari karena tidak semua ibu yang melahirkan IUFD terdata di RSUD Arifin Achmad Pekanbaru sehingga terjadi kesalahan dalam penelitian.

\section{Variabel Independen yang tidak Berhubungan dengan Kejadian IUFD}

Dari 5 variabel independen hanya 1 variabel yang tidak berhubungan secara signifikan dengan kejadian IUFD yaitu variabel usia ibu. Hasil penelitian ini sama dengan hasil penelitian yang dilakukan dengan Kongkoli (2008) bahwa tidak ada hubungan yang signifikan antara usia ibu dengan kejadian IUFD, hal ini kemungkinan adanya bias seleksi yang tidak dapat dihindari. Bias yang sulit dikendalikan akibat kesalahan klasifikasi sampel atau bias seleksi terjadi dimana tidak semua ibu yang melahirkan dengan IUFD terdata oleh petugas kesehatan di RSUD Arifin Achmad Pekanbaru.

\section{KESIMPULAN}

Variabel yang berhubungan sebab akibat dengan kejadian IUFD yaitu Ibu yang memiliki kadar $\mathrm{Hb}<11$ gr\% menyebabkan terjadinyaIUFD3 kali dibandingkan ibu yang memiliki kadar $\mathrm{Hb} \geq 11 \mathrm{gr} \%$ dan Ibu yang memiliki paritas 0 dan paritas $>4$ menyebabkan terjadinya IUFD 1,5 kali dibandingkan ibu yang memiliki paritas $1-4$. Variabel yang berhubungan terbalik dengan kejadian IUFD Ibu yang lama kehamilannya $\leq 40$ minggu menyebabkan terjadinya IUFD 2,5 kali dibandingkan ibu lama kehamilannya $>40$ minggu dan Ibu yang tidak memiliki komplikasi kehamilan menyebabkan IUFD2,5 kali dibandingkan ibu yang memiliki komplikasi kehamilan.

\section{SARAN}

Berdasarkan variabel yang berhubungan yaitu pada variabel kadar $\mathrm{Hb}$ dan paritas diharapkan kepada tenaga kesehatan untuk melakukan penyuluhan oleh tenaga kesehatan tentang bahaya anemia pada ibu hamil, memotivasi untuk mengkonsumsi makanmakanan yang banyak mengandung zat besi, meningkatkan pelayanan ANC oleh tenaga kesehatan yaitu melalui standar $14 \mathrm{~T}$. Penyuluhan dan konseling KB oleh tenaga kesehatan dengan MKJP (MOW/MOP). Diharapkan kepada ibu hamil dan keluarga untuk dapat mengusahakan selalu melakukan pemeriksaan ANC secara lengkap dan teratur serta berperan aktif dalam program KB. Untuk variabel yang berhubungan secara negatif pada variabel lama kehamilan dan komplikasi kehamilan yaitu Mengusahakan ibu agar dapat segera memeriksakan kehamilan sejak dini ketika menstruasi terlambat sekurang-kurangnya 1 bulan supaya dapat memastikan lama kehamilannya serta menganjurkan kepada tenaga kesehatan untuk bekerjasama dengan petugas KUA dalam melakukan penyuluhan tentang Kesehatan Reproduksi Pranikah kepada Calon Pengantin salah satunya tentang Siklus Menstruasi yang bertujuan untuk mengingat HPHT serta menganjurkan seluruh ibu hamil agar melakukan rujukan segera ke RSUD Arifin Achmad Pekanbaru apabila ada komplikasi kehamilan. Untuk variabel yang tidak berhubungan yaitu pada variabel usia ditujukan kepada pihak RSUD Arifin Achmad agar kegiatan AMP lebih dimantapkan dan ditingkatkan untuk mengurangi AKP.

\section{UCAPAN TERIMA KASIH}

Ucapan terima kasih ditujukan kepada Pembimbing I yaitu Prof. Dr. dr. Buchari Lapau, MPH dan Pembimbing II yaitu Asniati, A.Kep, M.Kes yang telah meluangkan waktu, tenaga dan pendapat untuk memberikan bimbingan serta bantuan kepada peneliti, Direktur RSUD Arifin Achmad Pekanbaru yang telah memberikan izin penelitian, dan seluruh Staff Prodi Magister IKM yang telah membantu secara moril.

\section{DAFTAR PUSTAKA}

Badan Litbangkes, Depkes RI. (2001). Standar Minimal Pelayanan Antenatal Care. Jakarta.

Kongkoli, E.Y. (2008). Analisis Faktor Yang Berhubungan Dengan Kematian Janin di Rumah Sakit Ibu Anak Siti Fatimah Kota Makasar Periode 2001-2002. Jurusan Keperawatan Politeknik Kesehatan Makasar dalam Sulolipu Edisi XVI: Makasar.

Lapau, B. (2007). Prinsip Dasar Epidemiologi. Jakarta.

Lindsey. (2008). Evaluation Of Fetal Death. Diakses dari http://www.medicine.medscape.com pada tanggal 9 Januari 2012. 
Nurchotimah. (2008). Anemia dan IUFD. Diakses dari www.blogspot.compada tanggal 28 Maret 2012.

Prawirohardjo, S. (2007). Ilmu Kebidanan Edisi Ketiga Cetakan Kesembilan. Yayasan Bina Pustaka Sarwono Prawirohardjo: Jakarta.

Rekam Medik. (2011). Data 15 Penyakit Terbesar di Irna Camar I dan II Tahun 2009-2011. RSUD Arifin Achmad Propinsi Riau: Pekanbaru.
Saefudin. (2010). Ilmu Kebidanan. Yayasan Bina Pustaka Sarwono Prawirohardjo: Jakarta.

Winkjosastro. (2005). Ilmu Kebidanan Edisi Ketiga Cetakan Ketujuh. Yayasan Bina Pustaka Sarwono Prawirohardjo: Jakarta.

Winkjosastro. (2007). Ilmu Kebidanan. Yayasan Bina Pustaka Sarwono Prawirohardjo: Jakarta. 